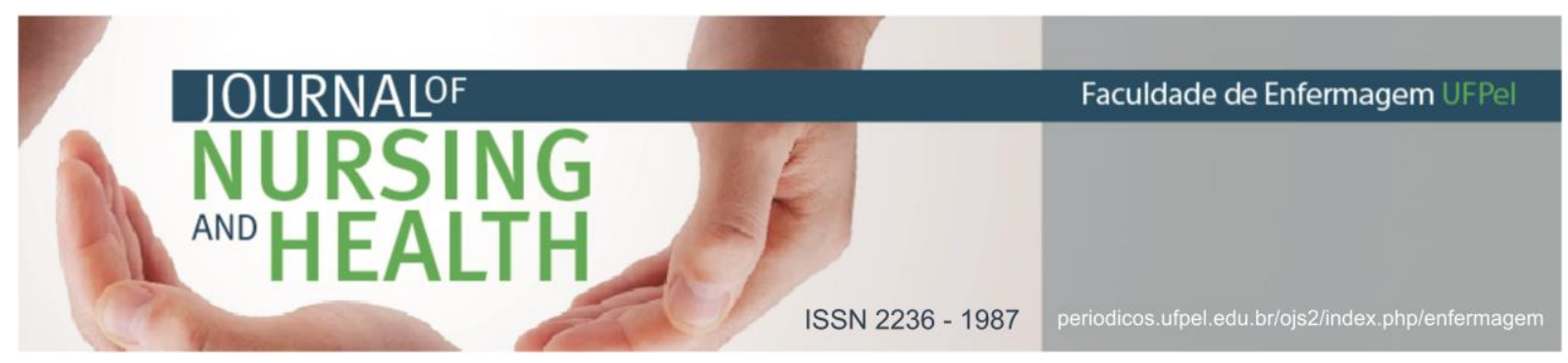

ARTIGO ORIGINAL

\title{
Percepção de enfermeiros da Estratégia de Saúde da Família sobre segurança do paciente
}

\author{
Family Health Strategy nurses' perception of patient safety \\ Percepción de enfermeros de la Estrategia de Salud de la Familia sobre seguridad del \\ paciente
}

Souza, Luccas Melo루 da Silva, Maria Cristina Sant’Anna²; Zavalhia, Sibele da Rosa³; Coppola, Isabella dos Santos ${ }^{4}$; da Rocha, Bárbara Paloschi ${ }^{5}$

Como citar este artigo Souza LM, da Silva MCS, Zavalhia SR, Coppola IS, da Rocha BP. Percepção de enfermeiros da Estratégia de Saúde da Familia sobre segurança do paciente. J. nurs. health. 2018;8(2):e188205

\section{RESUMO}

Objetivo: conhecer a percepção de enfermeiros da Estratégia de Saúde da Família sobre segurança do paciente. Métodos: pesquisa qualitativa, realizada em 2016 com 10 enfermeiros, no sul do Brasil, por meio de entrevistas submetidas à Análise de Conteúdo. Resultados: salienta-se a falta de familiarização dos enfermeiros com o assunto. Erros de medicação e quedas foram problemas à segurança dos pacientes e a comunicação efetiva fator promotor. A capacitação das equipes, implementação de instrumentos próprios voltados à segurança do paciente e diminuição da sobrecarga de trabalho foram apontadas enquanto estratégias de melhoria para a segurança do paciente. Considerações finais: o tema segurança do paciente ainda não faz parte da assistência dos enfermeiros da Saúde da Família, mas esses percebem sua importância. Uma cultura de segurança precisa ser implementada nos serviços mediante capacitação desses profissionais por meio de parceria com instituições de ensino.

Descritores: Enfermagem; Atenção primária à saúde; Saúde pública; Segurança do paciente; Erros médicos.

\section{ABSTRACT}

Objective: to understand the Family Health Strategy nurses' perception of patient safety. Methods: qualitative research was conducted in 2016 with 10 nurses, in southern Brazil, through interviews submitted to Content Analysis. Results: the nurses' lack of familiarity with the subject is highlighted. Medication errors and falls were problems to patient safety and effective communication is a promoting factor. The training of teams, implementation of own instruments focused at patient safety and reduction of work overload were pointed out as improvement strategies

\footnotetext{
${ }^{1}$ Enfermeiro. Doutor em Enfermagem. Universidade Federal de Ciências da Saúde de Porto Alegre (UFCSPA). Email: luccasms@gmail.com http://orcid.org/0000-0003-1629-9935

2 Enfermeira. Mestre em Enfermagem. Universidade Luterana do Brasil (ULBRA). E-mail: mcrisil@terra.com http: / /orcid.org/0000-0002-2714-4341

${ }^{3}$ Enfermeira. Hospital Porto Alegre. E-mail: beli_zavalhia@hotmail.com http://orcid.org/0000-0001-7134-1564

4 Estudante do curso de Enfermagem. Universidade Luterana do Brasil (ULBRA). E-mail: bella_coppola@hotmail.com http://orcid.org/0000-0002-6579-3393

5 Estudante do curso de Enfermagem. Universidade Luterana do Brasil (ULBRA). E-mail: barbarapaloschi@gmail.com http://orcid.org/0000-0002-6885-8690
} 


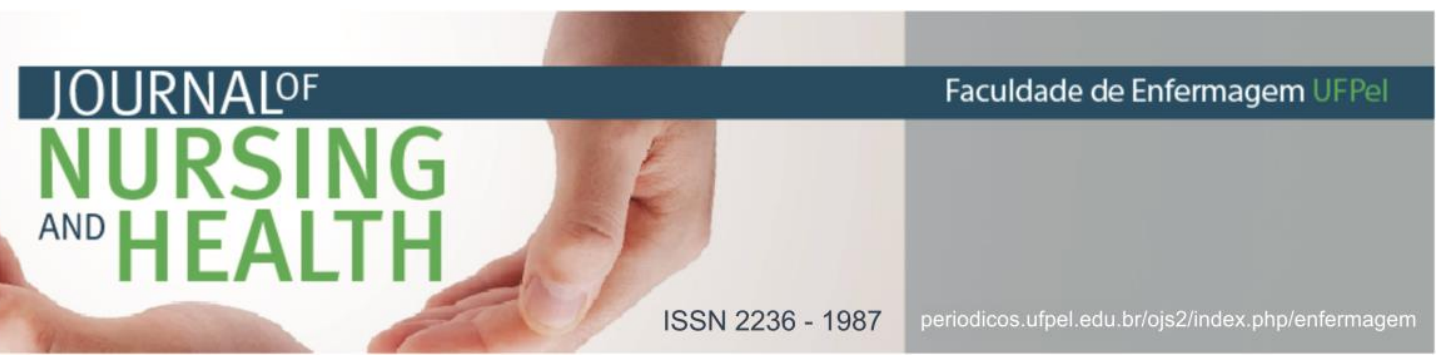

for patient safety. Final Considerations: the theme of patient safety is not yet part of the assistance of Family Health nurses, but they realize the importance of this. A safety culture needs to be implemented in services by training nurses through partnership with educational institutions.

Descriptors: Nursing; Primary health care; Public health; Patient safety; Medical errors.

\section{RESUMEN}

Objetivo: comprender la percepción de los enfermeros de Estrategia Salud de la Familia sobre seguridad del paciente. Métodos: investigación cualitativa realizada en 2016 con 10 enfermeros, en el sur de Brasil, por entrevistas presentadas al análisis de contenido. Resultados: la falta de familiarización de los enfermeros con el tema, errores de medicación y caídas eran problemas para la seguridad de los ellos y la comunicación eficaz factor promotor. La potenciación de los equipos, aplicación de instrumentos orientados a la seguridad y reducción de la sobrecarga de trabajo son señaladas como estrategias para mejorar la seguridad. Consideraciones Finales: el tema de seguridad del paciente no forma parte de la asistencia prestada por los enfermeros de la Salud de la Familia, pero se dan cuenta de su importancia. Una cultura de la seguridad debe ser implementada en los servicios por la formación de estos profesionales con una parcería con las instituciones educativas.

Descriptores: Enfermería; Atención primaria de salud; Salud pública; Seguridad del paciente; Errores médicos.

\section{INTRODUÇÃO}

O termo "segurança do paciente" remete à redução do risco de dano desnecessário, até um mínimo aceitável, na assistência em saúde. Esse mínimo diz respeito ao que é possível aceitar frente aos recursos disponíveis, ao conhecimento corrente e ao contexto em que ocorre a assistência, diante do risco de não tratar ou de utilizar outra forma de tratamento. ${ }^{1-2}$

No início dos anos 2000, a segurança do paciente tornou-se internacionalmente reconhecida como uma dimensão essencial da qualidade em saúde, entrando para a agenda de pesquisadores. Assim, a Organização Mundial da Saúde (OMS) estabeleceu a Aliança Mundial para a Segurança do Paciente, em 2004, como um programa para coordenar, facilitar e acelerar as melhorias na segurança do paciente em nível global. Busca, também, definir e identificar as prioridades na área da segurança do paciente em diversas partes do mundo, bem como contribuir para uma agenda internacional para a pesquisa no campo. . $^{2,-6}$

No Brasil, iniciativas de algumas instituições e de movimentos em rede, como a Rede Brasileira de Enfermagem e Segurança do Paciente (REBRAENSP) e o Centro Colaborador para a Qualidade do Cuidado e Segurança do Paciente (PROQUALIS), contribuíram para impulsionar as discussões e estratégias no âmbito público e privado, culminando na criação do Programa Nacional de Segurança do Paciente (PNSP), em 2013, e seus protocolos. ${ }^{2,7}$

Contudo, a existência de diretrizes e protocolos não garante a assistência segura, pois, além disso, é preciso desenvolvimento e compromisso contínuos para uma cultura de segurança do paciente, com sua amplitude e complexidade. ${ }^{7}$ Tal cultura resulta da associação de 


\section{JOURNALOF \\ NURSING \\ AND}

ISSN 2236 - 198

explicitando

a

escassez

investigações nesse contexto. ${ }^{10}$

Nos diferentes contextos dos serviços de saúde, o enfermeiro exerce funções de liderança, gerência e assistência. Nesse sentido, pode ser considerado como facilitador no processo de identificação de riscos à segurança do paciente, 0 que 0 configura como elemento chave nesse processo pelo seu sólido protagonismo na assistência. ${ }^{4}$ Isso evoca a necessidade de realização de pesquisas sobre segurança do paciente com enfermeiros da APS, a fim de conhecer como eles são percebidos e avaliados pelos profissionais implicados na assistência direta ao paciente.

Diante desse contexto, elaborouse como questão de pesquisa: qual a percepção de enfermeiros da ESF acerca da segurança do paciente nesse locus? Para responder tal questionamento, o presente estudo objetiva conhecer a percepção de enfermeiros da ESF acerca do tema segurança do paciente, a fim de contribuir para a criação de subsídios teóricos em prol da elaboração de estratégias de assistência para a promoção da cultura de segurança do paciente no contexto da ESF.

\section{MATERIAIS E MÉTODOS}

Estudo exploratório-descritivo, com abordagem qualitativa, cujo campo de estudo foram seis Unidades de Saúde da Família (USF) adscritas à Secretaria Municipal de Saúde (SMS) da Região Metropolitana de Porto AlegreRS. Foram entrevistados 10 enfermeiros, de um total de 45 , os quais estavam lotados nessas seis USF, do total de 18 que o município possui. 
Os enfermeiros foram sorteados aleatoriamente, de forma manual $e$ cega, tendo como critério que no máximo fossem estrevistados dois enfermeiros por ESF. 0 término das entrevistas ocorreu pela saturação dos dados, ou seja, quando não surgiram novas informações após as entrevistas com os sujeitos. $O$ sorteio foi realizado à medida que cada entrevista era realizada. Foi utilizado, como critério de inclusão, a aprovação no contrato probatório, a fim de evitar a entrevista com enfermeiros recém-contratados e com pouca experiência no serviço de saúde. E, o critério de exclusão foi estar em situação de afastamento do trabalho durante a realização do estudo.

Foi empregada a técnica da entrevista semiestruturada, realizada mediante roteiro pré-elaborado, contendo questões que abordavam a cultura de segurança do paciente, Eventos Adversos (EA), protocolos e educação continuada no tema do estudo. As entrevistas ocorreram entre os meses de abril e junho de 2016; foram agendadas com antecedência, via contato telefônico ou eletrônico, e realizadas individualmente em lugar que garantiu a privacidade do enfermeiro, no seu local e turno de trabalho. 0 tempo médio de duração das entrevistas foi de 16 minutos. Todas foram realizadas por um único entrevistador, sendo gravadas em mídia eletrônica. Os registros foram transcritos na íntegra e passaram por processo descritivo e analítico, seguindo as etapas propostas pela técnica de Análise de Conteúdo de Bardin. ${ }^{13}$
Os princípios éticos foram respeitados, levando em consideração as determinações das Normas de Pesquisa em Saúde vigentes no País. Foi utilizado o Termo de Consentimento Livre e Esclarecido, em duas vias, e o projeto foi aprovado por Comitê de Ética em Pesquisa, via Plataforma Brasil, recebendo o Certificado de Apresentação para Apreciação Ética n. ${ }^{\circ}$ 54328016.6.0000.5349.

Para manter a privacidade e 0 anonimato dos entrevistados, foram empregados codinomes iniciados por ENF, relacionados à palavra enfermeiro, seguidos por uma sequência numérica aleatória, sem caracterizar a sequência das entrevistas. Além disso, não se identificou o local de procedência dos entrevistados.

\section{RESULTADOS E DISCUSSÃO}

Os enfermeiros possuíam experiência média de trabalho na APS de 10,4 anos; a faixa etária variou entre 27 e 52 anos de idade. A análise das entrevistas permitiu organizar as informações em duas categorias: a) Cultura e Ações de Segurança do Paciente na ESF; e b) Segurança do Paciente na ESF: o que avançar?

\section{Cultura e ações de segurança do paciente na ESF}

Essa categoria veio à tona a partir dos questionamentos sobre como os enfermeiros percebiam e entendiam a temática segurança do paciente, no que diz respeito a conceitos, cultura e ações/estretágias desenvolvidas no contexto da ESF. 
Os enfermeiros associaram a prevenção de doenças e a promoção da saúde como atitudes que evidenciam a cultura de segurança do paciente, ressaltando, como fatores protetores, a segurança física e a avaliação da saúde como um todo.

[Segurança do paciente] é tentar manter a saúde das pessoas nesse âmbito de prevenção $e$ de promoção de saúde. (ENF1)

Eu vejo tanto a segurança física do paciente, o paciente integrado ao contexto da unidade, quanto à segurança dos procedimentos, daquilo que não é tão invasivo. Então, é mais difícil na Saúde Pública, porque é uma área mais aberta [ampla]. Eu vejo que, nessa área, as pessoas (profissionais) não se ligam muito nesse detalhe [segurança], que não deixa de ser muito importante. (ENF3)

Eu acho que é garantir o atendimento. Não só 0 atendimento, mas o acompanhamento de saúde dele [paciente], garantindo o bemestar desde um procedimento, usando a técnica necessária de assepsia com o material, até no que vai envolver a avaliação da saúde dele como um todo. (ENF4)

Contudo, mencionaram falta de familiarização com o tema, alegando que o assunto passa despercebido por ser ampla a atuação na ESF. Para eles:

Eu não conhecia este tema. Para mim é novo [...], mas dentro desse contexto de segurança, eu acho
ISSN $2236-1987$

que na Atenção Básica tem algumas coisas que a gente faz sem dar nome. Muitas vezes, a gente já faz essa ação. [...] talvez a gente tivesse até que parar $e$ olhar para o nosso trabalho [...], dar nome para uma coisa que já se faz [...] mas, eu nunca tinha trabalhado com esse nome [segurança do paciente]. Eu acho que está embutido no trabalho, entra em todos os assuntos, mas não é uma coisa direta assim: Ah! Vamos falar, agora, especificamente sobre este tema. (ENF 2)

Embora, no Brasil, a enfermagem seja precursora nas discussões sobre a segurança do paciente, com destaque, desde 2008, para as ações da REBRAENSP, a cultura de segurança do paciente ainda não é reconhecida e o tema não costuma ser abordado pelos enfermeiros entrevistados. A justificativa, para eles, decorre de ainda ser nova a implantação da ESF (ano de 2006) no município:

É um tema que a gente não aborda muito na Saúde da Família [...]. Então, tem a cultura de [...] como não tem muitos procedimentos [na ESF], tem mais medicações, a segurança é vista como [...] não acontecer algum incidente. [...] não tem ainda uma cultura, acho que a cultura é não se falar sobre isso. (ENF 8)

A Estratégia de Saúde da Família, tem 10 anos aqui no município, que para a Saúde Pública é muito novo. Até as pessoas conseguirem ter a ideia de como funciona, 


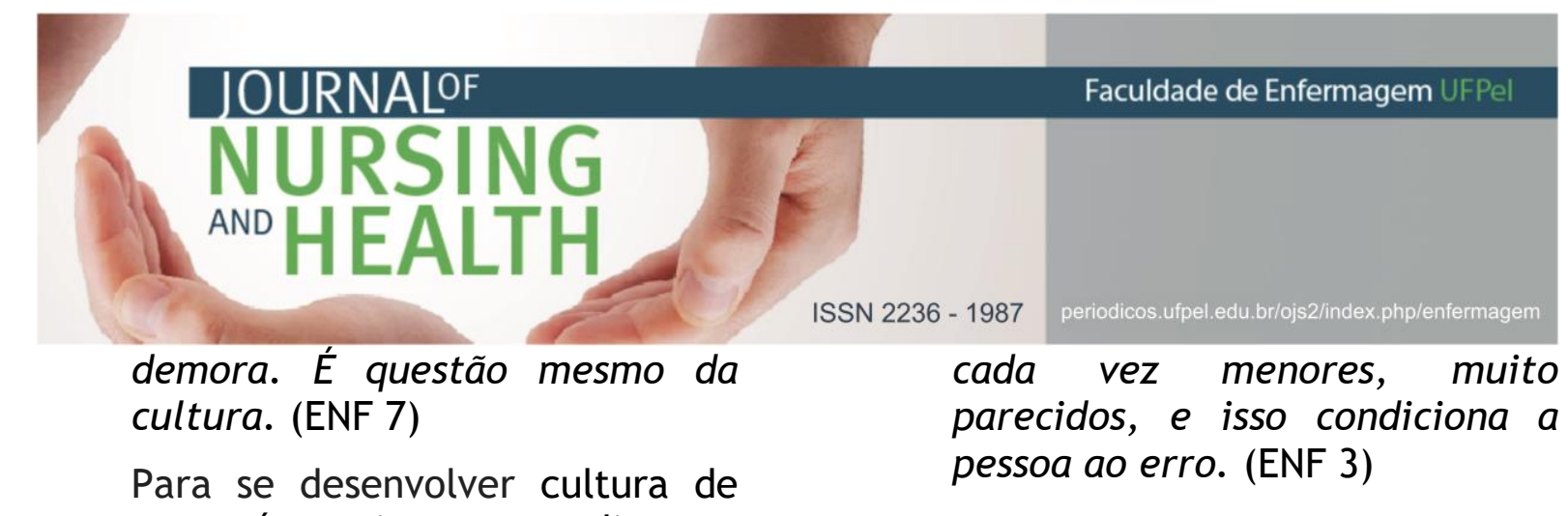
segurança, é preciso o entendimento das crenças e dos valores, bem como das normas que a instituição considera importantes, além de quais atitudes e comportamentos relacionados à segurança do paciente podem ser apoiados, recompensados e esperados. ${ }^{5-6}$

Ademais, para uma sólida cultura de segurança, é imprescindível o compromisso para discutir e aprender com os erros, reconhecendo a inevitabilidade deles ocorrerem, a identificação das ameaças ocultas, visando eliminá-los ou diminuí-los a um mínimo aceitável. Também é importante a incorporação de um sistema para o relato e a análise dos eventos adversos (EA) que não seja punitivo e que não remeta à culpa. ${ }^{5,6}$

EA é todo o incidente que resulta em dano ao paciente. ${ }^{1}$ Mas o termo ainda causa confusão entre os profissionais, sendo comumente relacionado a erro. Embora os entrevistados não sinalizem explicitamente as metas clássicas de segurança do paciente (avaliação da identificação do paciente, de queda, de comunicação efetiva, da administração de medicamentos, da higienização das mãos, das lesões por pressão), implicitamente reconhecem alguns desses, especialmente os erros na administração de medicamentos:

O evento adverso que a gente corre maior risco aqui é quanto às medicações. $\mathrm{Na}$ realidade, a vacina é o que nos move aqui. [...] o que influi muito são os rótulos

Evento adverso para mim é um erro que poderia ser evitado, como a troca de prontuários, a administração de uma medicação equivocadamente ou vencida. [...] Têm vários Joãos, e às vezes pega-se o prontuário de um João, separa-se ele na correria, e ele é de outro João. [...] Temos uma planilha com checklist, da conferência dos vencimentos das medicações, das caixas de urgência, de parada [cardiorespiratória] infantil e adulto, e de medicações. (ENF 4)

0 sistema de medicação é complexo. Isso se deve à necessidade do cumprimento de vários processos: de prescrição, armazenamento, dispensação e administração do medicamento. ${ }^{14} \mathrm{Se}$ tais processos não forem observados corretamente, acarretarão em erros nos serviços de saúde, com sérias consequências para os pacientes, para as instituições de saúde e para a sociedade.

Por conseguinte, a fim de se minimizar os erros com medicamentos, todos os processos devem ser planejados, padronizados e acompanhados, da mesma forma que a educação permanente, o uso de recursos de tecnologia da informação e as práticas profissionais relativas às etapas do processo. ${ }^{15}$

Quanto à ocorrência de incidentes relacionados à segurança do paciente na ESF, os enfermeiros mencionaram que a avaliação da situação gera a tomada de uma decisão 
sobre o ocorrido. Eles tentam manter uma postura ética e sem préjulgamento, conversando com os profissionais envolvidos, procurando saber os motivos que determinaram o incidente, conforme explicitado por ENF3:

Acho que tem que deixar bem claro para as pessoas [profissionais] o que é a segurança, o risco que as pessoas [os pacientes] correm. O risco que o profissional corre também, porque às vezes ele não se dá conta até acontecer o incidente. (ENF 3)

A queda foi um incidente salientado pelos entrevistados. Seja a partir das consultas ou das visitas domiciliares, mencionaram a orientação e a discussão sobre a prevenção de quedas como ação considerada promotora de segurança aos pacientes, de acordo com as falas:

Eles [as pessoas idosas e as obesas] perdem o equilíbrio; gestantes, também. Elas podem ter algum risco aqui, dentro da unidade. Não só aqui, em casa, na rua, em qualquer lugar. Mas, aqui, seria muito feio deixar uma pessoa cair ou ter algum tipo de acidente. [...]. Quando chove os pisos ficam escorregadios, porque as sombrinhas vêm pingando [...]. O tapete em casa, por exemplo, pode estar resvalando [...]. (ENF 7)

Quando o paciente está passando mal, a gente (deve) ter alguma proteção, por na maca, por uma proteção lateral, nunca deixar os pacientes sozinhos em sala de observação nem na nebulização. (ENF8)

Então, eu acho que já vem desde lá da entrada [na USF]. A questão de acessibilidade envolve segurança. A questão do piso escorregadio, de não ter mobília com quina, se o paciente se bater, se é um paciente que tem dificuldade de deambular. (ENF 10)

Vários fatores estão associados a um risco aumentado de queda. Logo, é preciso realizar a avaliação multifatorial do paciente, que consiste na identificação de fatores predisponentes da pessoa (intrínsecos) e do ambiente (extrínsecos). ${ }^{16}$

Devido aos possíveis danos que podem advir de quedas, os profissionais de saúde defrontam-se com o desafio de reduzir a ocorrência delas em todos os níveis de assistência ao paciente. Portanto, precisam implementar medidas para avaliar o risco, para garantir a assistência multiprofissional em ambiente seguro e para promover a educação do paciente e seus familiares, bem como dos profissionais. ${ }^{17}$

Nos serviços de saúde, ocorre uma mudança na abordagem relativa à segurança do paciente, uma vez que ela substitui a culpa e a vergonha, sentimentos comuns em caso de erros e danos aos pacientes, pela reflexão sobre os processos assistenciais, visando à prevenção de sua ocorrência. ${ }^{6}$ Como estratégia para lidar com esse tipo de problema, os entrevistados mencionaram a 


\section{JOURNAIOF \\ NURSING \\ ANO HEALTH

comunicação com os demais setores da

SMS e as reuniões internas:

A enfermeira, por sua vez, faz contato com a vigilância [Vigilância em Saúde]. Preenchemos toda a comunicação de erro; a Secretaria Estadual de Saúde (SES) nos dá retorno $e$ deixa essa mãe documentada com aquela vacina que foi feita errada [...]. Então, eles [SES] nos dão esse suporte. $E$ nós, [...] a gente sentou e fez um momento de reflexão. [...] é melhor que esse profissional [que cometeu $o$ erro] se afaste naquele momento do trabalho do que voltar estressado, voltar angustiado. (ENF 7)

A gente tem o procedimento de chamar esse profissional (que cometeu o erro), evoluir em ata essa conversa e, dependendo da gravidade da situação, se correr risco ao paciente, a gente entra em contato com a SMS. [...] é obrigatório abrir um processo administrativo junto à SMS. [...] Mas nunca se fica assim só na conversa, geralmente a gente tem que notificar. (ENF 8)

Conforme salientaram os entrevistados, a comunicação também se dá nas reuniões da equipe. Nessa ocasião, são relatados casos de pacientes vulneráveis, visando à solução ou à minimização de seus problemas, momento em que o tema segurança do paciente pode ser abordado, pois é a partir dessas reuniões que a equipe elege as prioridades a serem trabalhadas:
$\mathrm{Na}$ Estratégia, tem as reuniões semanais da unidade, [...] muito importantes para ver os casos pontuais, para ver o que a gente pode fazer para melhorar o posto (USF). Isso remete a segurança do paciente [...]. É a equipe, $e$ quando tu vês uma equipe que está coesa, que tem diálogo, que está junto, a segurança do paciente é muito mais abrangente. (ENF 1)

E quando fizermos reuniões, começarmos a trabalhar isso, expondo esta questão de segurança do paciente [...]. Então, na reunião, a gente puxa (aborda) isso: olha só, tem que ter cuidado e coisa e tal. (ENF 5)

Ainda sobre comunicação, os enfermeiros salientaram a importância de esclarecimentos aos pacientes sobre a função e identificação de cada profissional que atua na USF, para que o próprio paciente não se exponha a riscos. A comunicação permeia as atividades que integram a assistência à saúde, ${ }^{18}$ devendo ser efetiva. Para isso, visando à segurança ao paciente, a equipe precisa estar munida de habilidades e conhecimentos específicos:

Muitas vezes eles [pacientes] vêm e perguntam, questionam sobre 0 agente de saúde [Agente Comunitário de Saúde - ACS]. Por que o agente de saúde não vai até a casa verificar a pressão, o HGT, fazer algum procedimento? (ENF7)

Sobre os ACS, os enfermeiros consideraram a realização de busca ativa efetuada por esses como uma das 
medidas para a promoção da segurança do paciente, haja vista serem os ACS quem expõe os problemas da comunidade à equipe de saúde. Assim, segundo os entrevistados:

Se a gestante não vem, a gente [o ACS] faz a busca ativa, vai atrás. A criança que não fez vacina, a gente vai atrás [...] é tu estares atrás de uma pessoa [gestante] para fazer o pré-natal. É a segurança do paciente, segurança daquele bebê. Ir atrás da puericultura. (ENF 1)

Acho que a busca ativa feita pelos agentes é uma das estratégias que a gente tem para tentar promover a segurança. (ENF 9)

Os enfermeiros entrevistados também relataram que o desenvolvimento de ações básicas de adequação da estrutura física das USF e de promoção do conhecimento técnico do profissional que lá trabalha são ações promotoras de segurança, além do vínculo estabelecido entre os pacientes e os profissionais, do sigilo profissional e da preservação da privacidade do paciente. Dessa forma, consideram situações relacionadas à ética profissional (sigilo profissional e beneficência, por exemplo) como sendo questões de segurança do paciente, revelando 0 escasso conhecimento deste conceito e da própria cultura de segurança do paciente, conforme as falas:

[...] nas ações que se pratica, nas próprias consultas, tanto de enfermagem quanto médica. Vais fazer uma consulta querendo o bem, que aquele paciente melhore. E eu acho que, através do conhecimento técnico, tu vais desenvolver ações que promovam o bem-estar e a segurança do paciente. (ENF 9)

[...] a segurança do paciente vem desde o vínculo que ele tem com a equipe, a confiança, a certeza de que todas as informações que ele está passando aqui dentro da unidade serão sigilosas e que não vamos revelar [...] A gente não entrega exames a não ser para o indivíduo. Não se comenta, apesar de ser da família, diagnósticos com os familiares. $E$ para a consulta, só vai ser aceita a presença de outro familiar se a pessoa [o paciente] aceitar. (ENF 6)

Tudo na ESF envolve a orientação $e$ o vínculo com o paciente. Então, por mais que a gente faça, nunca é demais a questão da orientação, e a equipe toda deve falar a mesma linguagem. (ENF 8)

0 envolvimento do próprio paciente na segurança em serviços de saúde é um elemento fundamental para a qualidade assistencial. Nesse sentido, o Sistema Nacional de Vigilância Sanitária (SNVS) abriu frentes de comunicação com a sociedade, como o acesso à apresentação de suspeitas de irregularidades ao Sistema Eletrônico de Ouvidoria da Agência Nacional de Vigilância Sanitária (Anvis@tende), pela notificação de queixas técnicas, envolvendo a pós-comercialização de medicamentos, produtos para a saúde, saneantes e outros. Há também o Notivisa, direcionado especificamente 


\section{JOURNALOF \\ NURSING \\ AND HEALTH}

ISSN 2236 - 1987

ao paciente, ao acompanhante e à sociedade em geral. ${ }^{19}$

Logo, o paciente e a sua família necessitam estar seguros e empoderados quando buscam auxílio nas USF, e os profissionais que lá trabalham precisam ser seus facilitadores, adotando as melhores e mais seguras práticas assistenciais.

Sobre as práticas de segurança ao paciente, os entrevistados fizeram menção aos erros na administração de medicamentos e às quedas, enfatizando que, na APS, prevenção de doenças e promoção da saúde podem ser consideradas atitudes em prol da cultura de segurança dos pacientes, da mesma forma que efetuar a busca ativa desses pelos ACS. O tema segurança do paciente não costuma ser abordado pelos enfermeiros por considerarem que a APS é uma área ampla, cujas ações não são fragmentadas. A respeito de ações de segurança, salientaram a importância da comunicação na relação com os pacientes e nas reuniões de equipe.

Como estratégias para lidar com a questão da segurança ao paciente na $\mathrm{ESF}$, os entrevistados mencionaram a comunicação, principalmente durante as reuniões de equipe e nos esclarecimentos aos pacientes, o sigilo profissional e a busca ativa realizada pelos ACS.

\section{Segurança do paciente na ESF: o} que avançar?

As perguntas a respeito das estratégias que poderiam ser utilizadas para minimizar os incidentes que envolvem a segurança do paciente, bem como os protocolos utilizados e as medidas de educação permantente realizadas com vistas à segurança do paciente fizeram emergir a segunda categoria, a partir das falas que apontavam para ações a serem adotadas para uma melhor cultura de segurança do paciente na ESF.

A segurança do paciente é um componente fundamental da qualidade de cuidados de saúde, inclusive na ESF. Nesse sentido, como as organizações de cuidado esforçam-se continuamente para melhorar, há um reconhecimento crescente da importância e da necessidade de implantação de uma cultura de segurança do paciente nos serviços de saúde e da implantação de protocolos e utilização de indicadores assistenciais. $^{5}$

Os protocolos são ferramentas necessárias que favorecem a sistematização da assistência de enfermagem, convergindo para a excelência e para a segurança no cuidado ao paciente, sendo que esforços são feitos para identificar as melhores práticas e para estabelecer protocolos para o gerencimento do cuidado. ${ }^{17}$ Nessa perspectiva, a qualidade da assistência à saúde é uma meta atual das instituições, sendo avaliada, também, por intermédio dos indicadores de qualidade. Independentemente do nível de atenção à saúde, é essencial a utilização de indicadores e de protocolos como ferramentas assistenciais, pois evidenciam a necessidade de aprimoramento contínuo do cuidado de enfermagem e de renovação dos recursos humanos e tecnológicos. ${ }^{20}$ 
Mas, para alguns dos enfermeiros entrevistados, ainda há desconhecimento em relação à utilização de protocolos e indicadores de segurança do paciente. Eles alegam que, de certa forma, esses instrumentos estão contidos em outros protocolos de atenção à saúde, conforme as falas a seguir:

Não tem protocolo específico de segurança, não. Os protocolos que a gente segue são sempre os do Ministério [da Saúde]. Geralmente têm a ver com situações específicas. [...] Os indicadores que a gente sabe são quantitativos, números de exames, o próprio programa da Estratégia, [...] o e-SUS, que tu consegues fazer relatórios para saber o tipo de atendimento. Mas, sobre segurança, específico, não. (ENF 1)

A gente tem até os protocolos que o município aderiu, de atenção à saúde. Dentro desses protocolos, tem algumas coisas, por exemplo, tem ali um protocolo de saúde mental, onde tem a prevenção do suicídio, mas nada específico só de segurança. $\mathrm{Na}$ Saúde da Família, não tem essa fragmentação de uma coisa, está embutido dentro de um bolo, de um monte de coisas. (ENF 2)

Para auxiliar e instruir as instituições de saúde e seus profissionais, a Portaria MS/GM $n^{\circ} 529$, de 2013, estabeleceu um conjunto de protocolos básicos de segurança do paciente, definido pela OMS, que deve ser implantado. Assim, foram publicados seis protocolos pelo Ministério da Saúde, com o intuito de orientar os profissionais na ampliação da segurança do paciente nos serviços de saúde, e que precisam ser compartilhados e utilizados, também, na APS, ${ }^{21}$ apesar de não mencionados pelos entrevistados.

Todavia, cientes da importância e necessidade de envolvimento com a segurança dos pacientes, uma parte dos enfermeiros sugeriu que o meio para avançar tal temática na ESF seria começar a trabalhar explícita e especificamente nela:

Eu acho que a gente teria que criar algo voltado para a nossa realidade, como ela é, não como deveria ser. (ENF 3)

A gente tem um regimento interno de enfermagem que fala [aborda] algumas coisas, mas eu acho que deveria ter algo mais específico [sobre segurança] na ESF. (ENF 5)

Esse algo mais específico mencionado, voltado à realidade local, que os entrevistados não sabem denominar, são os protocolos institucionais de segurança, estratégias utilizadas para diminuir a ocorrência de eventos adversos. Tais protocolos são instrumentos para construir uma prática assistencial segura, pois envolvem a avaliação permanente e proativa dos riscos nos serviços de saúde, a identificação dos incidentes e a investigação das causas, bem como o estabelecimento de medidas efetivas para evitar ocorrências. 
Os entrevistados sugeriram que o tema segurança do paciente fosse mais abordado com as equipes, visando à melhoria do atendimento, conforme o disposto na fala a seguir:

Então, talvez a primeira coisa a se fazer seria apresentar, para as equipes, o assunto, falar o que é, de onde vem [...]. Acho que a primeira estratégia tem que ser essa, pois, para eu discutir um assunto, eu tenho que o conhecer. Teria que trabalhar com as equipes esse tema [segurança do paciente]. (ENF 2)

Nesse sentido, a criação de Núcleos de Segurança do Paciente e a vinculação desses às redes de apoio proporcionariam estímulo e suporte aos profissionais de saúde para a implementação da cultura de segurança do paciente na ESF do município onde foi realizada esta pesquisa.

Tais profissionais podem sentir-se pouco instrumentalizados para lidar com os erros ocorridos nos serviços de saúde onde trabalham, pois erros costumam estar associados a sentimentos de incapacidade, culpa, vergonha, além de limitado conhecimento científico. Portanto, a educação permanente destaca-se como componente essencial para o aperfeiçoamento nos cuidados de saúde prestados.

Todavia, questões alheias ao profissional, mas inerentes ao serviço, podem repercutir na segurança do paciente, como o dimensionamento quantitativo de profissionais:
$\mathrm{Na}$ minha unidade são duas equipes. $8 \mathrm{mil}$ pessoas [cadastradas no serviço]. Era para ter duas enfermeiras, mas estou apenas eu. [...] Em tempo integral, só eu. [...] Tem um dentista [...]. Então, os profissionais ficam acumulados [sobrecarregados] nas suas funções, $e$ isso nos deixa passíveis de erro. (ENF 1)

A gente precisa primar muito pela qualidade. Eu posso dizer que, se eu atender 10 pacientes em uma hora, a qualidade vai ser muito ruim. [...] Porque eu não vou conseguir ver o paciente como um todo. (ENF 7)

Os enfermeiros ressaltaram a sobrecarga profissional como um fator que afeta a segurança do paciente, uma das razões da importância de um dimensionamento de pessoal adequado. As condições de trabalho das equipes de saúde caracterizadas, por vezes, pela sobrecarga, são fatores de risco para a segurança do paciente, o que precisa mudar, pois compromete a qualidade do cuidado. ${ }^{22}$

Para uma prática assistencial segura aos pacientes atendidos na ESF, precisam ser contornados os problemas referentes, tanto ao desconhecimento dos entrevistados sobre a utilização de protocolos e indicadores específicos para esse fim, quanto à sobrecarga enfrentada por eles devido à insuficiência de profissionais para atender à demanda de pacientes.

\section{CONSIDERAÇÕES FINAIS}

A segurança do paciente ainda é um tema pouco abordado pelos 
enfermeiros da ESF entrevistados, apesar de a perceberem como inerente ao seu processo de trabalho. 0 desconhecimento sobre o assunto é explicitado sob a alegação de que ele passa despercebido na assistência realizada na ESF. Por não estarem familiarizados com a temática, se reportaram apenas aos temas clássicos, como erros de medicação e quedas, e não souberam distinguir erro de evento adverso.

Os enfermeiros entrevistados salientaram a importância da comunicação no espaço profissional, do vínculo, da confiança e do trabalho dos ACS como fatores que contribuem para evitar riscos à segurança do paciente.

Em geral, os enfermeiros demonstraram interesse em começar a trabalhar a temática, sugerindo que as reuniões semanais da equipe podem ser aproveitadas para introduzi-la, a fim de criarem uma cultura de segurança favorável no serviço, que perpassa pela elaboração de instrumentos específicos para a assistência na ESF.

Os enfermeiros precisam conscientizar-se do seu papel nas unidades de saúde, incitando a busca pelo conhecimento, tanto para si quanto para os demais componentes da equipe, no que tange às práticas seguras na assistência em saúde. Assim, sugerem-se estratégias que podem ser utilizadas na capacitação dos profissionais: praticar a comunicação efetiva, assessorar-se da legislação vigente sobre segurança do paciente, adequar os protocolos existentes para a realidade da ESF no município. Além disso, podem-se estabelecer parcerias com docentes, integrando a assistência, ensino e pesquisa em prol da segurança dos pacientes.

Os resultados desse estudo embora relevantes por abordarem e aprofundarem a percepção de enfermeiros da ESF acerca do tema segurança do paciente - precisam ser interpretados considerando as limitações do estudo. A amostra reduzida de profissionais (decorrente do critério de saturação dos dados) e a sua realização com enfermeiros de um contexto específico, não permitem generalizações, mas instigam reflexões e abrem perspectivas para novas pesquisas.

\section{REFERÊNCIAS}

1 Brasil. Ministério da Saúde (MS). Documento de referência para o Programa Nacional de Segurança do Paciente [Internet]. Brasília: ANVISA; 2014 [acesso em 2018 jun 13]. Disponível em: http://bvsms.saude.gov.br/bvs/public acoes/documento_referencia_progra ma_nacional_seguranca.pdf

2 Silva AT, Alves MG, Sanches RS, Terra FS, Resck ZMR. Assistência de enfermagem e o enfoque da segurança do paciente no cenário brasileiro. Saúde debate [Internet]. 2016[acesso em 2018 jun 13];40(111):292-301. Disponível em: http://www.scielo.br/scielo.php?scrip $\mathrm{t}=\mathrm{sci}$ arttext\&pid $=\mathrm{S} 0103$ -

$11042016000400292 \& \operatorname{lng}=$ pt\&nrm=iso

3 World Health Organization (WHO). Guide for Developing National Patient Safety Policy and Strategic Plan [Internet]. Brazzaville (Congo): World 


\section{JOURNALOF \\ NURSING

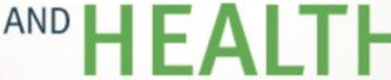

ISSN 2236 - 1987

de segurança do paciente. Revista uningá [Internet] 2017[acesso em 2018 mai 13];54(1):37-44. Disponível em: http: / / revista.uninga.br/index.php/u ninga/article/view/5

9 Marchon SG, Mendes Junior WV. Tradução e adaptação de um questionário elaborado para avaliar a segurança do paciente na atenção primária em saúde. Cad saúde pública (online) [Internet]. 2015 [acesso em 2018 jun 13];31(7):1395-402. Disponível em: http: / /www.scielo.br/scielo.php?scrip $\mathrm{t}=\mathrm{sci}$ arttext\&pid=S0102-

$311 \times 2015000701395 \& \operatorname{lng}=e n$

10 Mesquita KO, Silva LCC, Lira RCM, Freitas CASL, Lira GV. Segurança do paciente na atenção primária à saúde: revisão integrativa. Cogitare enferm [Internet]. 2016[acesso em 2018 mai 13];21(2):01-8. Disponível em: http://revistas.ufpr.br/cogitare/articl e/view/45665

11 Marchon SG, Mendes Junior WV, Pavão ALB. Características dos eventos adversos na atenção primária à saúde no Brasil. Cad saúde pública (online) [Internet]. 2015[acesso em 2018 mai 13];11(31):2313-30. Disponível em: http://www.scielo.br/scielo.php?pid= S0102-

311X2015001102313\&script=sci_abstra ct\&tlng=pt

12 Marchon S, Mendes Junior WVM. Segurança do paciente na atenção primária à saúde: revisão sistemática. Cad saúde pública (online) [Internet]. 2014[acesso em 2018 mai 13];30(9):121. Disponível em: http://www.scielo.br/pdf/csp/v30n9 /pt_0102-311X-csp-30-9-1815.pdf
8 Silva PL, Guimarães TMM, Carvalho OLSE, Carvalho NAR, Pereira PSL, Andrade KGF, et al. Produção científica no Brasil acerca da cultura 


\section{JOURNALOF \\ NURSING \\ AND 는}

ISSN 2236 - 198

13 Bardin L. Análise de Conteúdo. Lisboa: Edições 70; 2016.

14 Aizenstein $M$, Tomassi $M H$. Problemas relacionados a medicamentos; reações adversas a medicamentos e erros de medicação: a necessidade de uma padronização das definições e das classificações. Rev ciênc farm básica apl [Internet]. 2011 [acesso em 2018 mai 18];32(2):169-73. Disponível em: http://servbib.fcfar.unesp.br/seer/index.php/Ci en_Farm/article/viewFile/2066/1099

15 Llapa-Rodriguez EO, Silva LSL, Menezes MO, Oliveira JKA, Currie LM. Assistência segura ao paciente no preparo e administração de medicamentos. Rev gaúch enferm [Internet]. 2017 [acesso em 2018 jun 13];38(4):e2017-0029. Disponível em: http://www.scielo.br/scielo.php?scrip $\mathrm{t}=\mathrm{sci}$ arttext\&pid=S1983-

$14472017000400408 \& \operatorname{lng}=p t \& n r m=i s o$

16 Borba DLL, Lange C, Llano PMP, Maahg SB, Viegas AC, Santos BP. Perfil das idosas atendidas por queda em um serviço de emergência. J nurs health [Internet]. 2017 [acesso em 2018 jun 02];7(1):67-77. Disponível em: https://periodicos.ufpel.edu.br/ojs2/ index.php/enfermagem/article/view/ 7499/7092

17 Correa AD, Marques IAB, Martinez MC, Santesso PL, Leão ER, Chimentão DMN. Implantação de um protocolo para gerenciamento de quedas em hospital: resultados de quatro anos de seguimento. Rev esc enferm USP [Internet]. 2012 [acesso em 2017 jul 02];46(1):67-74. Disponível em: http://www.scielo.br/pdf/reeusp/v46 n1/v46n1a09.pdf
18 Souza LM, Herberts D, Silva DM, Schilling MC. Atualização em segurança do paciente: comunicação e segurança do paciente. Revista sul brasileira de enfermagem. 2017;24:38-44.

19 Brasil. Agência Nacional de Vigilância Sanitária (ANVISA). Análise dos dados das notificações para o indicador de infecção em corrente sanguínea em unidade de terapia intensiva $-1^{\circ}$ semestre 2011. Boletim informativo: segurança do paciente e qualidade em serviços de saúde [Internet]. fev 2012[acesso 2017 jul 02];04(II):1-22. Disponível em: http://portal.anvisa.gov.br/document s/33852/272031/Boletim+Seguran\%C3 $\% A 7 a+d o+p a c i e n t e+e+q u a l i d a d e+e m+s$ ervi\%C3\%A7os+de+sa\%C3\%BAde++Ano+II+n\%C2\%BA04/fe69c049-03644ad4-9cf9-f4cb111810be?version=1.1.

20 Galhardi NM, Escobar EMA. Indicadores de qualidade de enfermagem. Rev ciênc med (Campinas) [Internet]. 2015. [acesso em 2018 jul 24];24(2):75-83. Disponível em: https://seer.sis.puccampinas.edu.br/seer/index.php/cien ciasmedicas/article/view/2639

21 Ministério da Saúde (BR). Portaria $\mathrm{n}^{\circ}$ 529, de $1^{\circ}$ de abril de 2013. Institui o Programa Nacional de Segurança do Paciente (PNSP) [Internet]. Brasília; 2013 [acesso em 2017 jul 02]. Disponível

em: http: / /bvsms.saude.gov.br/bvs/saude legis/gm/2013/prt0529_01_04_2013.h tml.

22 Oliveira RM, Leitão IMTA, Silva LMS, Figueiredo SV, Sampaio RL, Dondim MM. Estratégias para promover segurança do paciente: da identificação dos riscos às práticas 
baseadas em evidências. Esc anna nery [Internet]. 2014 [acesso em 2018 jun 02];18(1):122-29. Disponível em: http://www.scielo.br/scielo.php?pid= S1414-

$81452014000100122 \&$ script=sci_abstra ct\&tlng=pt

Data de submissão: 18/05/2018

Data de aceite: 07/08/2018

Data de publicação: 01/10/2018 